Revista de Investigación de Física 23(3), (2020)

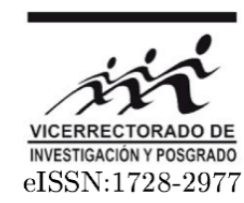

Use of HEC-HMS in floodwave propagation simulations

\author{
Jorge Bueno Galdo ${ }^{1, *}$ \\ ${ }^{1}$ AECOM Corporation \\ Recibido 05 febrero 2020 - Aceptado 02 diciembre 2020
}

\begin{abstract}
A delicate feature of the flood propagation simulation performed by the program HEC-1 with the option of the modified Puls method with normal flow approximation is constituted by the estimation of the quanta parameter NSTPS. While it is recognized to be a parameter that one should calibrate, it is usually recommended that it be estimated as the ratio (wave travel time/integration time step). In this paper it is shown that numerical experiments conducted with the program FEQ, retained as standards, when compared with HEC-1 solution, do not confirm the above estimate. The preliminary results presented here suggest that the ratio (time to peak of outflow hydrograph/time to peak of inflow hydrograph) may be a more meaningful, but strongly event dependent,parameter.
\end{abstract}

Keywords: Hydraulics.

\title{
Uso del HEC-HMS en la simulación de ondas de avenida
}

\begin{abstract}
Resumen
Una característica delicada en la simulación de propagación de inundaciones realizada por el programa HEC-1 con la opción del método Puls modificado con aproximación de flujo normal está basado en la estimación del parámetro de cuantia NSTPS. Si bien se reconoce que es un parámetro que se debe calibrar, generalmente se recomienda estimarlo como la relación (tiempo de viaje de onda / intervalo de tiempo de integración). En este trabajo se muestra que los experimentos numéricos realizados con el programa FEQ, considerados como estándares, cuando se comparan con la solución HEC-1, no confirman la estimación mencionada lineas arriba. Los resultados preliminares presentados aquí sugieren que la relación (tiempo al pico del hidrograma de flujo de salida / tiempo al pico del hidrograma de flujo de entrada) puede ser un parámetro más significativo, pero fuertemente dependiente del evento.
\end{abstract}

Palabras clave: hidráulica

1 jorge.bueno@aecom.com 


\section{Introduction}

The program HEC-HMS has been designed to simulate the response of a watershed to precipitation events. One of the components of the river network is the channel reach or river reach where the process of wave propagation can be simulated by several routing methods. One method in particular is the object of this research: the modified Puls method (Puls, 1928) with normal depth storage vs. outflow relationship, which has its basis in hydraulics concepts. We will call this method "modified Puls method \#2" for short, to distinguish it from the homonimous method \#1, where the storage vs. outflow relationship is given from empirical data. In this method one assumes that a river reach can be simulated globally and that the inflow hydrograph $\mathrm{I}(\mathrm{t})$ and outflow hydrograph $\mathrm{O}(\mathrm{t})$ are related to the storage $\mathrm{S}(\mathrm{t})$ in the reach via the continuity equation

$$
\frac{\partial S(t)}{\partial t}=f(t)-O(t)
$$

Since this equation is not sufficient to solve the problem of wave propagation through the reach, another relationship between $\mathrm{S}, \mathrm{I}, 0$ should be found. This can be given only by hydraulics (correctly the de SaintVenant equations), but other drastic simplifications (as the Muskigum method) are usually introduced in hydrology for the sake of expediency. A method that approximates the dynamic behavior of the system.is the one that assumes that $\mathrm{S}$ and 0 are indirectly related through the outflow cross section area A., via the momentum equation as written for normal flow.

$$
O=\frac{4.186}{n} \frac{A_{o}^{5 / 3}}{P_{o}^{2 / 3}} \sqrt{S f}
$$

where $\mathrm{Sr}$ is the "energy slope" at the outflow cross section, $\mathrm{n}$ is Manning's friction coefficient, Ao, is the outflow cross section area at the depth yo; Po is the length of its wetted perimeter, and yo(Ao) is the inverse function of $\mathrm{A}(\mathrm{yo})$; Ao, is related to $\mathrm{Sf}$ either via the equation $\mathrm{S}=\mathrm{LA}$, where $\mathrm{L}$ is the reach length, or via other more sophisticated relationships which introduce the inflow water area. The first published reference to this method of numerical approach to floodwave propagation has been found by the authors in (De Marchi, 1945) who gives credit to (Fantoli, 1925 ) for the "concetto informatore" (conceptual framework).

It is obvious that this type of routing has considerable simplifications with respect to a strict applications of the full de Saint-Venant equations, but one must admit that the application of HEC-HMSis sufficiently easy, with respect to full equation programs, to warrant a search for the limits within which HECHMS could be used for wave propagation studies of hydraulic consequence.

In the present project we specify the channel cross section (via 8 points, which is what the HEC-HMS modified Puls method \#2 requires), the channel's length, and the channel's slope, and we will consider several normal How conditions corresponding to normal depths varying from $5 \mathrm{ft}$ to $40 \mathrm{ft}$ at intervals of $5 \mathrm{ft}$. We will achieve this by varying the "unperturbed" flowrate Qo according to the Chezy-Manning Equation (2). We superpose then to each unperturbed normal How various hydrographs with variable characteristics of peak How $\triangle \mathrm{Qi}$ and time to peak Tp. By varying the only HECHMS parameter NSTPS for the simulation of the hydrograph propagation we will explore the region within which the results of HEC-HMS applications are reliable. In order to do this we need "standard" solutions against which to compare the HEC-HMS solutions. We will assume that these standard solutions are the solutions of the Full Equation Model (FEQ), developed by (Franz, 1988).

\section{Model Data}

The The geometry of the channel reach to model is presented in Figure 1. The bottom slope is $\mathrm{S}=.0002$ and the Manning's " $n$ " values are $n=0.030$ for the channel and $\mathrm{n}=0.80$ for the overbanks. The length of the channel reach is $\mathrm{L}=10$ miles. Since the initial conditions start from uniform How, we will choose as initial flowrates for our experiments, fractions of that flowrate which fills the channel in normal How conditions ( $Q o$ max $=128,046 \mathrm{cfs}$ ). The several unperturbed normal flowrate that are the object of our investigation are the normal discharges, for the same geometry, corresponding to depths that range from $5 \mathrm{ft}$ to $40 \mathrm{ft}$. They are presented in column 1 of Table 2 , paired with the corresponding normaldepths.

The resulting hydrographs (sum of the unperturbed flowrate Qo and of the perturbation hydrograph) have the analytic expression

$$
Q=Q_{o}+\Delta Q_{i}\left[\frac{t}{\tau_{p}}\right]^{2} e^{2}\left(t-\frac{t}{\tau_{p}}\right)
$$

Where: $\Delta$ Qi is the perturbed hydrograph peak and Tp is the perturbation hydrograph. The resulting hydrograph peak is therefore Qo $+\Delta$ Qi. The values of $\Delta$ Qi have been established so that the normal depth corresponding to $\mathrm{Q} 0+\Delta \mathrm{Qi}$ has a value between $5 \mathrm{ft}$ and $40 \mathrm{ft}$, at intervals of $5 \mathrm{ft}$. This is tantamount to 
Rev. Inv. Fís. 23(3), (2020)

saying that, if we call Qoi the $j$-th value of the unperturbed normal discharge the following relationship issatisfied

$$
Q_{o, j}+\Delta Q_{i j}=Q_{o i+j}
$$

This paper reports on the results of the experiments conducted with

$$
Q_{o, 2}=10,525 c f s
$$

${ }^{1} \Delta Q_{12}=10,921 c f s$, for several values of the parameters $\Delta \mathrm{t}$ (time increment of the numerical integration scheme), TP (time to peak), and NSTPS (number of sub-reaches used in the HEC-HM Ssimulation). The simulation deals with a flood wave which, starting from a normal depth of $10 \mathrm{ft}$, presents a peak stage of $15 \mathrm{ft}$. The values of the integration time step $\Delta \mathrm{t}$ used in the simulation are presented in the following matrix (Table 2), juxtapposed to the Tp values to which theyrefer.

Since the values of $\mathrm{Q} 0$ and $\Delta \mathrm{Qi}$ are kept constant throughout this presentation, we will refer to each one of the numerical experiments by the triplet $\mathrm{Tp}$, $\Delta \mathrm{t}$, NSTPS. We will denote, e.g., by "experiment $(\mathrm{Tp}=2 \mathrm{hr}, \Delta \mathrm{t}=15 \mathrm{~min}, \mathrm{NSTPS}=3)$ " the experiment whose parameters have the values given within the parentheses.

\begin{tabular}{|c|c|c|c|c|c|c|c|}
\hline \multicolumn{3}{|l|}{ Qoj (cfs) } & \multicolumn{5}{|c|}{ Qoj+ $+\Delta \mathrm{Qij}(\mathrm{cfs})$} \\
\hline $\begin{array}{c}\text { Yoj } \\
\text { (feet) }\end{array}$ & $\Delta \mathrm{Q} 1 \mathrm{j}$ & $\Delta Q_{2 j}$ & $\Delta \mathrm{Q} 3 \mathrm{j}$ & $\Delta \mathrm{Q} 4 \mathrm{j}$ & $\Delta \mathrm{Q} 5 \mathrm{j}$ & $\Delta \mathrm{Q6j}$ & $\Delta \mathrm{Q} 17$ \\
\hline 3,194 & 10,525 & 21,446 & 35,866 & 54,816 & 76,475 & 100,936 & 128,046 \\
\hline 5 & 7,331 & 18,252 & 32,672 & 51,622 & 73,281 & 97,742 & 124,852 \\
\hline 10,525 & 21,446 & 35,866 & 54,816 & 76,475 & 100,936 & 128,046 & \\
\hline 10 & 18,252 & 32,672 & 51,622 & 73,281 & 97,742 & 124,852 & \\
\hline 21,466 & 35,866 & 54,816 & 76,475 & 100,936 & 128,046 & & \\
\hline 15 & 32,672 & 51,622 & 73,281 & 97,742 & 124,852 & & \\
\hline 35,866 & 54,816 & 76,475 & 100,936 & 128,046 & & & \\
\hline 20 & 51,622 & 73,281 & 97,742 & 124,852 & & & \\
\hline 54,816 & 76,475 & 100,936 & 128,046 & & & & \\
\hline 25 & 73,281 & 97,742 & 124,852 & & & & \\
\hline 76,475 & 100,936 & 128,046 & & & & & \\
\hline 30 & 97,742 & 124,852 & & & & & \\
\hline 100,936 & 128,046 & & & & & & \\
\hline 35 & 124,852 & & & & & & \\
\hline 128046 & & & & & & & \\
\hline 40 & & & & & & & \\
\hline
\end{tabular}

Table 2. Parameter for Input Hydrographs

Table 2. Time Step for Simulation

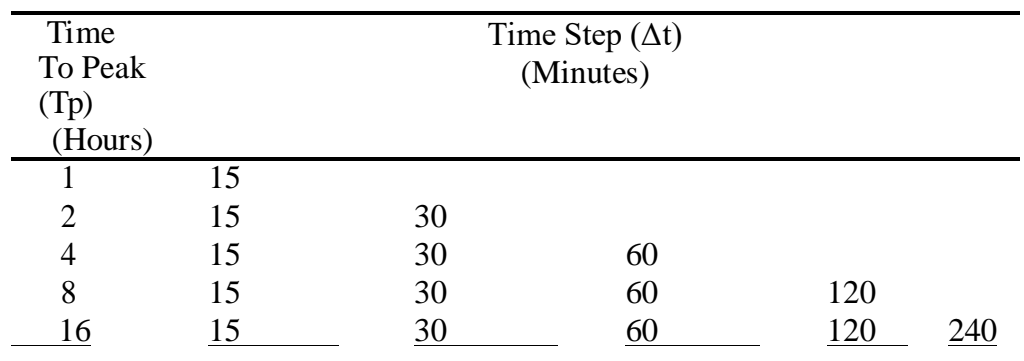




\section{Presentation of the results}

By inspecting the results of the numerical experiments presented in the last column of Table 3, we discover that the value of $\Delta t$ does not affect sensibly the results of the simulation, as far as the value of NSTPS is concerned. This can be seen clearly in comparing the Figures 5, 6, 7 where, for Tp $=4 \mathrm{hrs}, \Delta \mathrm{t}$ varies from $15 \mathrm{~min}$ to $60 \mathrm{~min}$. Notice that in our simulations the value of $\Delta t$ is always at most as large as $\mathrm{Tp} / 4$, and it is therefore reasonable that the above result be expected.

The results of the numerical experiment $(\mathrm{Tp}=1 \mathrm{hr}$, $\Delta \mathrm{t}=15 \mathrm{~min}$ ) for several values of the parameter NSTPS, compared with the standard solution obtained by means of FEQ (Bueno-Galdo, 1991), shows clearly that the parameter NSTPS affects dramatically the outcome of the simulation. The peak of the response and the time to peak of the response tend to increase as the value of NSTPS increases. Notice that for NSTPS $=1$ the outflow hydrograph cuts the inflow hydrograph at the peak of the outflow hydrograph (because in this case the routing is identical to level pool routing). For this experiment it seems that a value of NSTPS $=3$ fits best the standard solution, albeit the HEC-HMS result lags slightly with respect toit.

The several parameters defining the columns of Table 3 are described in detail below.

Columna I Tp, time to peak of the inflow hydrograph Columna II $\Delta$ t, time step of the HEC-HMSsimulation

Columna III T'p, time to peak of the outflow hydrograph as simulated by HEC-HMS, where the value of NSTPS isoptimal;

Columna IV NSTPSc $=\left(T^{\prime} p-T p\right) \Delta t$ value of NSTPS that one would obtain by the peak travel time (from inflow cross section to outflow cross section) by $\Delta \mathrm{t}$;

Columna V NSTPSv, value of NSTPS that one would obtain by dividing the reach length by the peak outflow

water velocity multiplied by. $\Delta \mathrm{t}$;

Columna VI NSTPSm, the value of NSTPS found

experimentally;

Columna VII NSTPSp, the value of NSTPS given by the

formula proposed below

NSTPSP $=\mathrm{n}+1$ if $\mathrm{T}^{\prime} \mathrm{p} / \mathrm{Tp}>\mathrm{n}+.2$

NSTPSP $=\mathrm{n} \quad$ if $\mathrm{T}^{\prime} \mathrm{h} / \mathrm{Tp}<\mathrm{n}+.2$,

where $\mathrm{n}$ is any integer.

\section{Conclusions}

The preliminary results of the investigation presented in this paper tends to suggest that the quanta parameter NSTPS used in the application of the modified Puls method \#2 to the HEC-HMS simulation of a floodwave propagation depend exclusively on the peak delay factor $\mathrm{T}^{\prime} \mathrm{p} / \mathrm{Tp}$. If this is the case, the parameter is not only a characteristic of the macro and microgeometry of the river reach, but it depends also on the characteristics of the inflow hydrograph. This means that NSTPS is different for different flood waves. If the floodwave has a large value of TP then NSTPS should have the value of 1 . If Tp is small, NSTPS should have values larger than 1 , according to the outcome of Equation (5). Since most floodwaves have several peaks, a choice of the value of NSTPS can be made to simulate more accurately single peaks or overall trends. The arbitrariness by which this process is clouded may constitute a major handicap for the use of the modified Puls method \#2 in the HECHMS simulation of hydraulically meaningful problems.

Table 3 . Results of Numerical Experiments

\begin{tabular}{cccccccc}
\hline Tp & $\Delta \mathrm{T}$ & T'p & NSTPSv & NSTPSv & NSTPSm & T'p/Tp & NSTPSp \\
\hline 1.00 & 15 & 3.5 & 10 & 17 & 3.00 & 3.50 & 4.00 \\
\hline 2.00 & 15 & 4.50 & 10 & 16 & 3.00 & 2.25 & 3.00 \\
& 30 & 4.50 & 5 & 8 & 2.00 & 2.25 & 3.00 \\
\hline 4.004 & 15 & 6.75 & 11 & 16 & 2.00 & 1.63 & 2.00 \\
& 30 & 6.50 & 5 & 8 & 2.00 & 1.50 & 2.00 \\
& 60 & 6.00 & 2 & 4 & 2.00 & 1.34 & 2.00 \\
\hline 8.00 & 15 & 10.75 & 11 & 15 & 2.00 & 1.34 & 2.00 \\
& 30 & 10.30 & 5 & 8 & 2.00 & 1.28 & 2.00 \\
& 60 & 11.00 & 3 & 4 & 2.00 & 1.38 & 2.00 \\
& 120 & 10.00 & 1 & 2 & 2.00 & 1.25 & 2.00 \\
\hline
\end{tabular}


Rev. Inv. Fís. 23(3), (2020)

\begin{tabular}{lccccccc}
\hline 16.00 & 15 & 18.50 & 10 & 15 & 2.00 & 1.15 & 1.00 \\
& 30 & 18.58 & 5 & 8 & 2.00 & 1.15 & 1.00 \\
& 60 & 19.00 & 3 & 4 & 2.00 & 1.19 & 1.00 \\
& 120 & 18.00 & 1 & 2 & 2.00 & 1.13 & 1.00 \\
& 240 & 20.00 & 1 & 1 & 1.00 & 1.25 & 1.00 \\
\hline
\end{tabular}

\section{References}

Puls, L. (1928). Flood Regulation of the Tennessee River, House Document No. 185, Pt. 2, Appendix B, 70th Congress, 1st Session, U.S. Government Printing Office, Washington, D.C.

De Marchi, G. (1945). Sull'Onda di Piena che Seguirebbe al Crollo della Diga di Cancano, L'Energia Elettrica, Vol. XXII, No. 8-9-10, pp. 157-169,Milano.

Fantoli, A. (1988). Sul Passaggio dell'Onda di Piena nella Supposta Rotta di un Serbatoio, Annali delle Acque Pubbliche, Roma.

Franz, D. (1988). Notes for Short Course and Input Description for FEQ, Schaumburg, Illinois, USA.
Bueno-Galdo, J. (2015). Hydrologic Model Study of the Essex Community Airport Potential Inundation. Essex, New Jersey, USA.

Bueno-Galdo, J. (1989). Solución de las Ecuaciones del Flujo No-Permanente, en Canales por el Método de Elementos Finitos, Universidad Nacional San Antonio Abad del Cusco, Perú. (Año Sabatico)

Bueno-Galdo, J. (1978). A Non-Simultaneous Equations Solution of the Dynamic Flood Equations, (Master of Science Thesis). University of Cincinnati, Ohio, USA.

Bueno-Galdo, J. (1991). Reliability of the Full Equation Model (FEQ) for the Solution of the Steady State and Unsteady Flows in Open Channels and Rivers. (Doctoral Thesis). Purdue University, USA 